A Comparison of Atomic Oxygen Erosion Yields of Carbon and Selected Polymers

Exposed in Ground Based Facilities and in Low Earth Orbit

Sharon K. Rutledge and Bruce A. Banks

Lewis Research Center

Cleveland, Ohio

and

Michael Cales

Cleveland State University

Cleveland, Ohio

Prepared for the

Aerospace Ground Testing Conference

sponsored by the American Institute of Aeronautics and Astronautics

Colorado Springs, Colorado, June 20-23, 1994

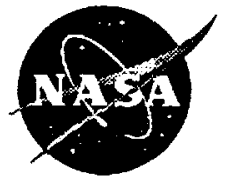

National Aeronautics and Space Administration
(NASA-TM-106622) A COMPARISON OF

ATOMIC OXYGEN EROSION YIELDS OF

CAR $9 O N$ AND SELECTEO POLYMERS

EXPOSED IN GROUND BASED FACILITIES

AND IN LOW EARTH ORBIT (NASA.

Lewis Research (enter) 9 p
N94-35243

Unclas

$63 / 27 \quad 0012650$ 


\title{
A COMPARISON OF ATOMIC OXYGEN EROSION YIELDS OF CARBON AND SELECTED POLYMERS EXPOSED IN GROUND BASED FACILITIES AND IN LOW EARTH ORBIT
}

\author{
Sharon K. Rutledge and Bruce A. Banks \\ NASA Lewis Research Center \\ Cleveland, Ohio \\ Michael Cales \\ Cleveland State University \\ Cleveland, Ohio
}

\begin{abstract}
A comparison of the relative erosion yields (volume of material removed per oxygen atom arriving) for FEP Teflon, polyethylene, and pyrolytic graphite with respect to Kapton $\mathrm{HN}$ was performed in an atomic oxygen directed beam system, in a plasma asher, and in space on the EOIM-III (Evaluation of Oxygen Interaction with Materials-III) flight experiment. This comparison was performed to determine the sensitivity of material reaction to atomic oxygen flux, atomic oxygen fluence, and vacuum ultraviolet radiation for enabling accurate estimates of durability in ground based facilities. The relative erosion yield of pyrolytic graphite was found not to be sensitive to these factors, that for FEP was sensitive slightly to fluence and possibly ions, and that for polyethylene was found to be partially VUV and flux sensitive but more sensitive to an unknown factor. Results indicate that the ability to use these facilities for material relative durability prediction is great as long as the sensitivity of particular materials to conditions such as VUV, and atomic oxygen flux and fluence are taken into account. When testing materials of a particular group such as teflon, it may be best to use a witness sample made of a similar material that has some available space data on it. This would enable one to predict an equivalent exposure in the ground based facility.
\end{abstract}

\section{Introduction}

Materials qualification for atomic oxygen durability for use in low Earth orbit has been performed in both ground based and in-space exposure facilities. The ground-based facilities have been developed out of the necessity to study long term atomic oxygen effects to levels greater than can be achieved with a typical Space Shuttle mission. They also have the advantage of quick turnaround, lower cost per exposure, and ease of tailorability to the specific application test condition of interest.

\footnotetext{
Copyright $(1994$ by the American Institute of Aeronautics and Astronautics, Inc No copyright is asserted in the United States under Title 17, U.S. Code. The U.S. Government has a royalty-free license to exercise all rights under the copyright claimed herein for Government purposes. All other rights are reserved by the copyright owner.
}

Some questions naturally occur about the applicability of ground based test data for use in predicting how a material will perform in low Earth orbit. There are concerns about the effects of acceleration of exposure to atomic oxygen, whether the presence of ionic species will cause anomalous results, effects of atomic oxygen energy, and others. The primary concern is whether or not ground based facilities can predict material loss close enough to that measured in low Earth orbit to be used as a reliable prediction tool. Ground based exposure facilities range from thermal plasmas to energetic directed beams ${ }^{1-7}$. There is currently no known facility which has the exact energy, species and state of atoms as present in low Earth orbit. None to date have been able to accurately demonstrate the erosion yields of materials as witnessed in low Earth orbit. The energy of the atoms $(4.5 \mathrm{eV})$ arrival in space due to the passage of spacecraft through the atmosphere is very difficult to achieve in a ground based facility. Energies easily achievable on the ground are generally thermal $(0.04 \mathrm{eV})$ or higher (10's to 100's of eV) due to physics limitations. Therefore, it is important to determine if similar material losses are achievable with these types of facilities, or if calibration values can be measured to enable reliable predictions.

A typical measure of degradation for unprotected materials is the erosion yield or number of cubic centimeters of material removed per arriving atom of atomic oxygen. Relative erosion yields were compared for four well characterized materials typical of those used in space. These materials (polyimide (Kapton HN), pyrolytic graphite, low oxygen content polyethylene, and fluorinated ethylene propylene (FEP Teflon)) were exposed in space on EOIM-III, in a commercial plasma asher under several operating conditions, and in the NASA LeRC Atomic Oxygen Directed Beam Facility. The material loss rates were measured and the erosion yields compared to that for polyimide Kapton. Kapton was selected for comparison because it has been well characterized in space. 


\section{Approach}

Materials:

Sample coupons, $2.54 \mathrm{~cm}$ diameter, were punched from $0.005 \mathrm{~cm}$ thick sheets of polyimide Kapton HN (DuPont), low oxygen content polyethylene (Consolidated Thermoplastics) and fluorinated ethylene propylene (FEP Teflon) (DuPont). Pyrolytic graphite disks approximately $2.54 \mathrm{~cm}$ in diameter by $0.2 \mathrm{~cm}$ thick from Union Carbide were also used for exposure testing. Identical materials were exposed in low Earth orbit and in each facility. All of the samples were fully dehydrated in vacuum and weighed prior to and after exposure in order to minimize errors in mass due to water absorption ${ }^{8}$.

\section{Plasma Asher:}

An SPI Plasma Prep II asher operated on air was used for the majority of the testing due to its ready availability on the market and ease of set-up. The asher operates using RF (13.56 $\mathrm{MHz}$ ) generated between two electrodes which surround a pyrex glass reaction chamber. The $R F$ creates a discharge which produces a thermal plasma of approximately $0.04 \mathrm{eV}$. The plasma contains some ions and excited states and vacuum ultraviolet radiation. The amounts and intensity of these have not been determined. The species generated are atomic and ionic oxygen and nitrogen. The nitrogen species have been shown earlier not to play a role in material reaction with the polymers tested ${ }^{8}$. Material loss rates were measured at two different pressures in the vacuum chamber ( $100 \mathrm{mtorr}$ and 500 mtorr). This pressure difference results in two different arrival rates of atomic oxygen and a shift in the shape of the plasma glow. A higher pressure produces more of a ring plasma in which samples are out of the glow and a low pressure produces a cylindrical plasma with the samples in the glow. Materials were also exposed inside of a tantalum Faraday cage so that atomic oxygen could enter the cage but the samples were significantly shielded from ions and the vacuum ultraviolet radiation from the plasma. This was accomplished by using an open re-entrant box which prevented line-of-sight exposure of the samples to the external air plasma. The various exposure conditions were used to determine what operating parameters significantly affect the relative reaction rates of typical polymer materials, and the conditions necessary to most closely duplicate those in low Earth orbit. Temperature in the plasma measured by a temperature indicating sensor strip placed between two glass slides was typically $65^{\circ} \mathrm{C}$. Temperatures inside the Faraday cage are expected to be higher.

\section{Atomic Oxygen Directed Beam Facility:}

The beam facility at NASA LeRC uses an Electron Cyclotron Resonance Plasma Source from Applied Science and Technology Inc. (ASTeX) operated on pure oxygen to generate a directed thermal energy beam of atomic oxygen with less than $1 \%$ ions at energies of typically $15-18 \mathrm{eV}$. The beam can expose a broad area (approximately $1000 \mathrm{~cm}^{2}$ ) to atomic oxygen. The source in addition to atomic oxygen generates $130 \mathrm{~nm}$ vacuum ultraviolet radiation. To study the effect of VUV radiation, a glass atomic oxygen beam focusing and VUV blocking apparatus ${ }^{1}$ was used during a portion of the exposures. VUV intensity was measured with an Acton Research photomultiplier and filter wheel. The instrument was calibrated to the intensity levels measured from a deuterium lamp. This lamp was calibrated by the National Institute of Standards. Sample temperature during exposure was measured by a temperature indicating sensor strip placed inside of a protective pocket made from a $0.0127 \mathrm{~cm}$ thick aluminum foil sheet.

\section{EOIM-III}

Samples of each material were exposed in low Earth orbit

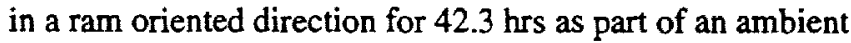
temperature sample tray on the EOIM-III flight experiment flown on STS-46. The samples received an atomic oxygen arrival of approximately $1.8 \times 10^{15}$ atoms $/ \mathrm{cm}^{2}-\mathrm{sec}$ for a total fluence of $2.6 \times 10^{20}$ atoms $/ \mathrm{cm}^{2}$. These values were determined through measurement of mass change of a Kapton witness coupon exposed on the sample tray.

\section{Test Design:}

Due to the complexity and time limitations placed on each test, it was necessary to carefully select the tests in order to achieve the most information for the minimum amount of testing. The Taguchi model for Design of Experiments ${ }^{9}$ was used to determine the most informative series of tests to perform in the ground based facilities. Samples of each material, wheneverpossible, were exposed at the same time so that the results between materials could be directly compared.

For the experiment design, three controllable independent factors (vacuum ultraviolet radiation intensity, atomic oxygen flux, and atomic oxygen fluence) were selected. These have been proposed by many to have the greatest effect on material erosion. Temperature may also have an influence, but it was not a controllable factor so it was only monitored during testing. Since testing time was limited, two levels (high and low) were selected for each factor. An L8 factorial design was used. Level selection was limited to the high and low ranges achievable in the facilities. The full series of tests were performed in the directed beam facility. In the plasma asher, a more limited test sequence (elimination of fluence as a factor due to testing limitations) was used to supplement the directed beam data. The EOIM-III flight sample exposure was fixed in terms of exposure parameters.

\section{Data Measurement and Analysis:}

Changes in mass were recorded for each material for each test run. This data was then used in equation 1 to determine the effective erosion yield for each material. The erosion yield was then divided by the known erosion yield for Kapton in low Earth orbit $\left(3 \times 10^{-24} \mathrm{~cm}^{3} /\right.$ atom) to obtain a measurement relative to a known standard. 


$$
\mathrm{EY}_{\mathrm{M}}=\frac{\mathrm{dM} / \mathrm{A}}{\rho^{*} \mathrm{~F}}
$$

Where:

$\mathrm{EY}_{\mathrm{M}}=$ Erosion yield for the material of interest $\left(\mathrm{cm}^{3} / \mathrm{atom}\right)$

$\mathrm{dM}=$ Change in mass of the material $(\mathrm{g})$

$A=$ Exposed surface area $\left(\mathrm{cm}^{2}\right)$

$\rho=$ Density of the material $\left(\mathrm{g} / \mathrm{cm}^{3}\right)$

$\mathrm{F}=$ Effective fluence (atoms $/ \mathrm{cm}^{2}$ )

Erosion yields were then plotted as a function of each factor to look for potential data trends. A regression model was fit for each material in order to look for the significant factors and the amount of error that could be explained by each factor. The computer program that was used for the regression model and analysis of variance (ANOVA) was STORM ${ }^{10}$. In the statistical analysis, R-squared values indicate goodness of fit of the computer generated model with the data. R-squared values range from 0 to 1.0 with 1.0 being a perfect fit. Correlation coefficients also range from 0 to 1.0 with 1.0 being a perfect correlation. This coefficient shows the amount of interaction between two factors. Two statistical measures were used to indicate the significance of a particular factor. The " $F$ " value is the measure of the mean square error due to the factor of interest divided by the mean square error due to all other factors. It is an indication of the extent to which the spread observed in the data can be explained by a particular factor. The probability or "p-value" is also an indicator of the same thing but it represents the probability that the factor is not significant. P-values of $<0.05(5 \%)$ are considered to be statistically significant.

\section{Results and Discussion}

The ratio of the erosion yields for polyethylene, FEP, and pyrolytic graphite relative to that for Kapton $\mathrm{HN}$ are shown in Table I. The error in the erosion yield ratio shown in the table for the beam facility data is the standard deviation based on the propagation of error in the measurement technique. For the plasma asher, the standard deviation for multiple tests at the same conditions was used to represent the error. Plots of the erosion yields relative to Kapton $\mathrm{HN}$ as a function of the three main factors for the directed beam exposure data are shown in Figures 1-3.

\section{Pyrolytic Graphite:}

The relative erosion yields for pyrolytic graphite, appear to be independent of the type of exposure facility used. This indicates that for carbon, the relative erosion yield is not as sensitive to the variations between exposure conditions, and can be adequately compared in ground based facilities in relation to low Earth orbit. Over the range tested, none of the factors were significant to the $5 \%$ level. F-values for each factor were 0.52 for VUV $(p=0.49), 0.13$ for flux $(p=0.72)$, and 3.1 for fluence $(\mathrm{p}=0.11)$.

\section{FEP Tefion:}

FEP teflon, however, showed a broad variation in erosion yield ratios relative to Kapton. When shielded in the Faraday cage in the plasma asher, the values much more closely matched the value observed in low Earth orbit. The relative erosion yields observed for samples exposed directly in the asher plasma and in all cases in the directed beam facility were much more closely related to each other.

Teflon has been thought to be more sensitive to VUV radiation effects than other materials due to the potential for crosslinking to take place. The data from the directed beam, however, indicates that this may not be the case for the energy and intensity levels used in these tests. Similar erosion yields were obtained at the same flux and fluence levels whether the samples were shielded from VUV radiation or not. In the shielded case, the VUV intensity matched fairly close the VUV intensity in space. However, the relative erosion yields were approximately a factor of 20 greater in the directed beam. Regression analysis of the directed beam data gives fairly strong support for an erosion yield fluence dependence with FEP. The relative erosion yield appears to increase slightly with increasing fluence. This may be due to the increased surface area with texturing allowing multiple opportunities for incoming atomic oxygen to react through partial trapping. The R-squared value for the fit was 0.83 and the only significant factor was the fluence with an F-value of $38.06(p=0.00027)$. Neither of the other factors were significant to the $5 \%$ level. F-values were 0.13 for VUV ( $p=0.73$ ) and 2.22 for flux $(\mathrm{p}=0.18)$.

It is unclear why the relative erosion yield for FEP shielded from the plasma in the asher is more in line with the EOIM-III data. Trying to fit all of the data for FEP results in a very poor fit $(R$-squared $=0.35)$ and no significant factors. There is a strong correlation between VUV and flux (Correlation coefficient of 0.7 ), but even taking this into account did not improve the fit. This provides strong evidence that there is some factor which affects the erosion yield of FEP which has not been taken into account. It is possible that ions or excited states in the plasma may play a role in accelerating the erosion yield or there may be other factors.

Knowing this discrepancy, the best way to test FEP in ground based facilities would probably be to use FEP as a witness coupon and calculate an effective FEP erosion yield using the known erosion data from low Earth orbit. 


\section{Polyethylene:}

Polyethylene gave the broadest range of relative erosion yields of the three materials and is the most difficult of the three to interpret. The plots of data from the directed beam visually indicate that there may be a slight inverse relationship between flux and erosion yield and VUV intensity and erosion yield. Regression analysis of the data, however, gives a poor fit (R-squared of 0.53 ). The only significant factor was the VUV intensity with an F-value of $6.8(p=0.04)$. This is surprising because it would seem that the flux should also be a significant factor, yet its' $F$-value was $1.14(p=0.33)$. The Fvalue for fluence was $0.016(p=0.91)$.

The data from the asher is even more confusing because the relative erosion yield inside the Faraday cage at low flux is approximately four times higher than that in the Faraday cage at high flux. The high flux data inside the Faraday cage more closely matches the relative erosion yields observed in the directed beam facility and in LEO on EOIM-III. Relative erosion yields obtained in the asher plasma are slightly higher than the space data. This indicates that there may be an additional factor or factors which play a stronger role in the asher erosion yield data than flux, VUV, or the presence of more or less ions or excited states. Possible differences in yields may be due to the presence of reaction products from nearby samples in the plasma, or some other effect.

It may be difficult to obtain clear information on polyethylene in an asher environment due to the inability to screen out specific factors, but directed beam exposure shows favorable agreement with space data for low flux and low VUV exposure.

\section{Conclusions}

A comparison of material loss for typical polymers exposed in space and ground based facilities indicates that the ability to use these facilities for material relative durability prediction is great as long as the sensitivity of particular materials to conditions such as VUV, flux and fluence are taken into account. When testing materials of a particular group such as Teflon, it may be best to use a witness sample made of a similar material that has some available space data on it. This would enable one to predict an equivalent exposure in the ground based facility. For pyrolytic graphite and polyethylene, it appears that material loss in space can easily be correlated with that in ground based beam systems. Although in a plasma asher, the yields for polyethylene may be slightly higher. Comparisons of this type between ground based facilities and space enables materials to be effectively screened on the ground where exposure and number of samples exposed can be better tailored to meet the types of information needed.

\section{Acknowledgements}

The authors would like to thank Joyce Dever at the NASA Lewis Research Center for providing measurements of the vacuum ultraviolet radiation intensity in the atomic oxygen directed beam.

\section{References}

1. Stidham, C.R.; et al. "Low Earth Orbital Atomic Oxygen Environmental Simulation Facility for Space Materials Evaluation", NASA TM-106128, 1993.

2. Johnson, C.L.; et al. "The Vanderbilt University Neutral O-Beam Facility", 18th International SAMPE Technical Conference Proceedings, Oct. 7-9, 1986.

3. Arnold, G.S.; Peplinski, D.R.; "A Facility for Investigating Interactions of Energetic Atomic Oxygen with Solids", Aerospace Report No. ATR-84(8540)-3, 1985.

4. Brinza, D.E.; et al. "Production of Pulsed Atomic Oxygen Beams Via Laser Vaporization Methods"; 18th International SAMPE Technical Conference Proceedings, Oct. 7-9, 1986.

5. Rempt, R.D.; "Production of a Beam of Ground State Oxygen Atoms of Selectable Energy"; 18th International SAMPE Technical Conference Proceedings, Oct. 7-9, 1986.

6. Sjolander, G.W.and Bareiss, L.E.; "Martin Marietta Atomic Oxygen Beam Facility"; 18th International SAMPE Technical Conference Proceedings, Oct. 7-9, 1986.

7. Caledonia, G.E.; et al. "A High Flux Source of Energetic Oxygen Atoms for Material Degradation Studies", AIAA 85-7015.

8. Rutledge, S.K.; et al. "An Evaluation of Candidate Atomic Oxygen Resistant Materials for Space Applications in LEO", NASA TM-100122, 1986.

9. Montgomery, D.C.; Design and Analysis of Experiments, 3rd Ed., John Wiley and Sons, 1991.

10. Emmons, H.; et al. STORM, Quantitative Modeling for Decision Support; Version 3.0; Storm Software Inc., 1992. 
Table I.-Relative Erosion Yields for FEP, Polyethylene, and Pyrolytic Graphite

\begin{tabular}{|c|c|c|c|c|c|c|c|}
\hline \multirow{2}{*}{$\begin{array}{l}\text { ATOMIC } \\
\text { OXYGEN } \\
\text { SOURCE }\end{array}$} & \multicolumn{4}{|c|}{ OPERATING CONDIIIONS } & \multicolumn{3}{|c|}{ EROSION YIELD RELATIVE TO KAPTON } \\
\hline & $\begin{array}{l}\text { TEMP. } \\
\left({ }^{\circ} \mathrm{C}\right)\end{array}$ & $\begin{array}{c}\text { VUV } \\
\text { INTENSITY } \\
\text { (suns) }\end{array}$ & $\begin{array}{c}\text { EFFECTIVE } \\
\text { FLUX } \\
\text { (atoms } / \mathrm{cm}^{2} \text {-sec) }\end{array}$ & $\begin{array}{c}\text { EFFECTTVE } \\
\text { FLUENCE } \\
\left.\text { (atoms } / \mathrm{cm}^{2}\right)^{*}\end{array}$ & $\begin{array}{l}\text { FEP } \\
\text { TEFLON }\end{array}$ & $\begin{array}{c}\text { POLY- } \\
\text { ETHYLENE }\end{array}$ & $\begin{array}{c}\text { PYROLYTIC } \\
\text { GRAPHITE }\end{array}$ \\
\hline \multirow{12}{*}{$\begin{array}{l}\text { DIRECTED } \\
\text { BEAM } \\
\text { FACILITY }\end{array}$} & $<41.6$ & 0.3 & $1.1 \times 10^{15}$ & $1.1 \times 10^{20}$ & $1.19 \pm 0.48$ & $1.70 \pm 0.08$ & $0.35 \pm 0.07$ \\
\hline & $<41.6$ & 0.3 & $9.2 \times 10^{14}$ & $4.4 \times 10^{20}$ & $1.46 \pm 0.14$ & $1.74 \pm 0.08$ & $0.19 \pm 0.01$ \\
\hline & $<41.6$ & 1.8 & $7.2 \times 10^{15}$ & $1.2 \times 10^{20}$ & $1.24 \pm 0.06$ & $1.34 \pm 0.07$ & $0.31 \pm 0.04$ \\
\hline & $<41.6$ & 1.8 & $5.4 \times 10^{15}$ & $3.9 \times 10^{20}$ & $1.56 \pm 0.08$ & $1.31 \pm 0.06$ & $0.25 \pm 0.02$ \\
\hline & 132 & 150.3 & $1.9 \times 10^{16}$ & $1.6 \times 10^{21}$ & - & - & $0.19 \pm 0.01$ \\
\hline & 132 & 151.3 & $2.0 \times 10^{16}$ & $1.2 \times 10^{21}$ & $\ldots$ & $\ldots$ & $0.23 \pm 0.01$ \\
\hline & $<41.6$ & 144.8 & $5.0 \times 10^{15}$ & $2.7 \times 10^{20}$ & $1.24 \pm 0.05$ & $1.13 \pm 0.05$ & $0.20 \pm 0.01$ \\
\hline & $<41.6$ & 143.9 & $4.2 \times 10^{15}$ & $2.1 \times 10^{20}$ & $1.37 \pm 0.06$ & $1.32 \pm 0.06$ & $0.20 \pm 0.02$ \\
\hline & 143 & 150.3 & $1.6 \times 10^{16}$ & $3.7 \times 10^{20}$ & $1.48 \pm 0.07$ & $1.22 \pm 0.06$ & $0.30 \pm 0.37$ \\
\hline & 143 & 150.3 & $1.6 \times 10^{16}$ & $1.1 \times 10^{20}$ & $1.24 \pm 0.07$ & $1.18 \pm 0.06$ & $0.28 \pm 0.04$ \\
\hline & $?$ & 150.3 & $2.0 \times 10^{16}$ & $4.3 \times 10^{20}$ & $1.57 \pm 0.07$ & - & $0.30 \pm 0.02$ \\
\hline & $?$ & 151.3 & $1.9 \times 10^{16}$ & $4.3 \times 10^{20}$ & $1.59 \pm 0.07$ & - & $0.29 \pm 0.02$ \\
\hline \multirow{4}{*}{$\begin{array}{c}\text { PLASMA } \\
\text { ASHER }\end{array}$} & 65 & HIGH & $2.7 \times 10^{16}$ & $2.3 \times 10^{20}$ & $0.63 \pm 0.07$ & $2.57 \pm 0.34$ & $0.21 \pm 0.03$ \\
\hline & 65 & HIGH & $6.0 \times 10^{15}$ & $6.2 \times 10^{19}$ & $1.30 \pm 0.17$ & $2.22 \pm 0.12$ & $0.29 \pm 0.03$ \\
\hline & $?$ & LOW & $1.3 \times 10^{16}$ & $1.4 \times 10^{20}$ & $0.27 \pm 0.05$ & $1.91 \pm 0.08$ & - \\
\hline & $?$ & LOW & $5.6 \times 10^{15}$ & $6.1 \times 10^{19}$ & $0.03 \pm 0.01$ & $4.81 \pm 0.08$ & $0.22 \pm 0.03$ \\
\hline EOIM-III & $?$ & 0.2 & $1.8 \times 10^{15}$ & $2.6 \times 10^{20}$ & $0.06 \pm 0.01$ & $1.60 \pm 0.10$ & $0.22 \pm 0.01$ \\
\hline
\end{tabular}

* Error in VUV intensity measurements may be as much as $50 \%$ for directed beam facility data and errors in flux and fluence measurements overall are less than $5 \%$. 


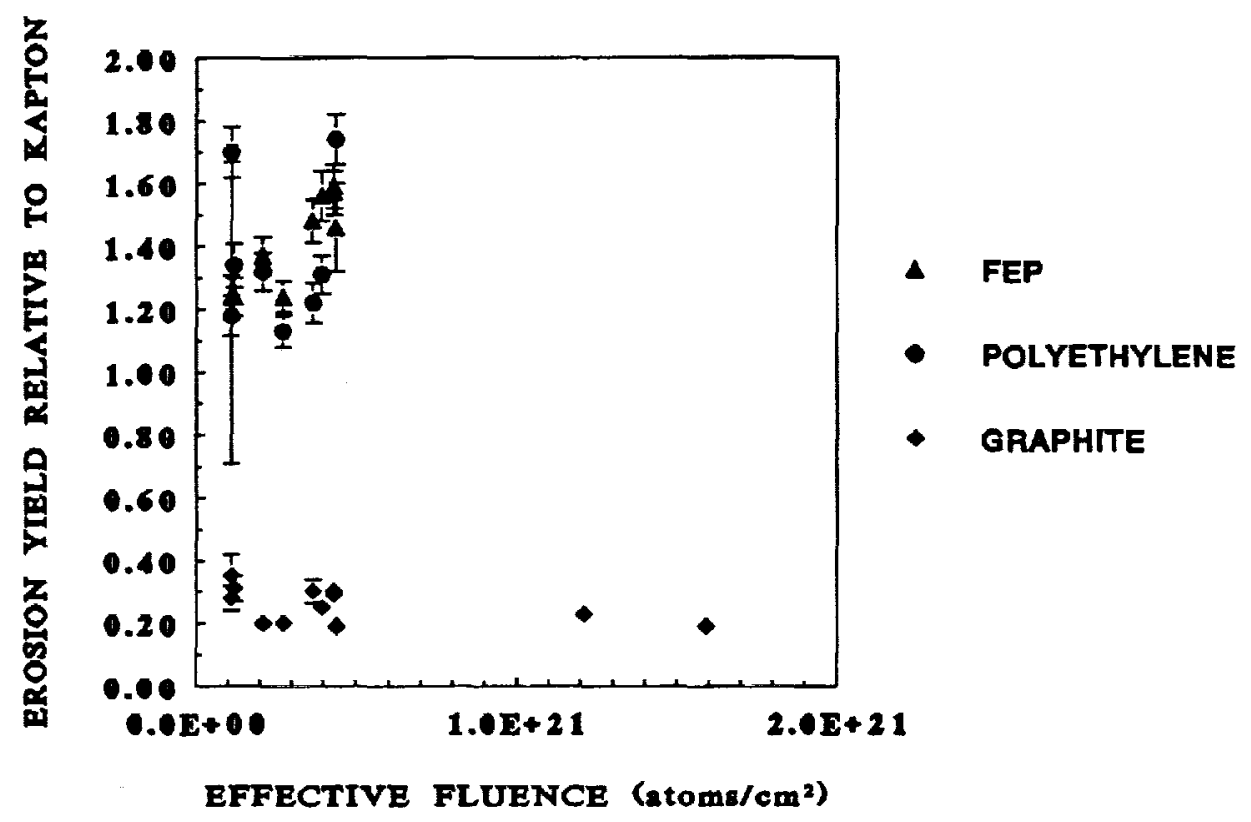

Figure 1.-Relative erosion yield dependence on effective atomic oxygen fluence in the directed beam facility.

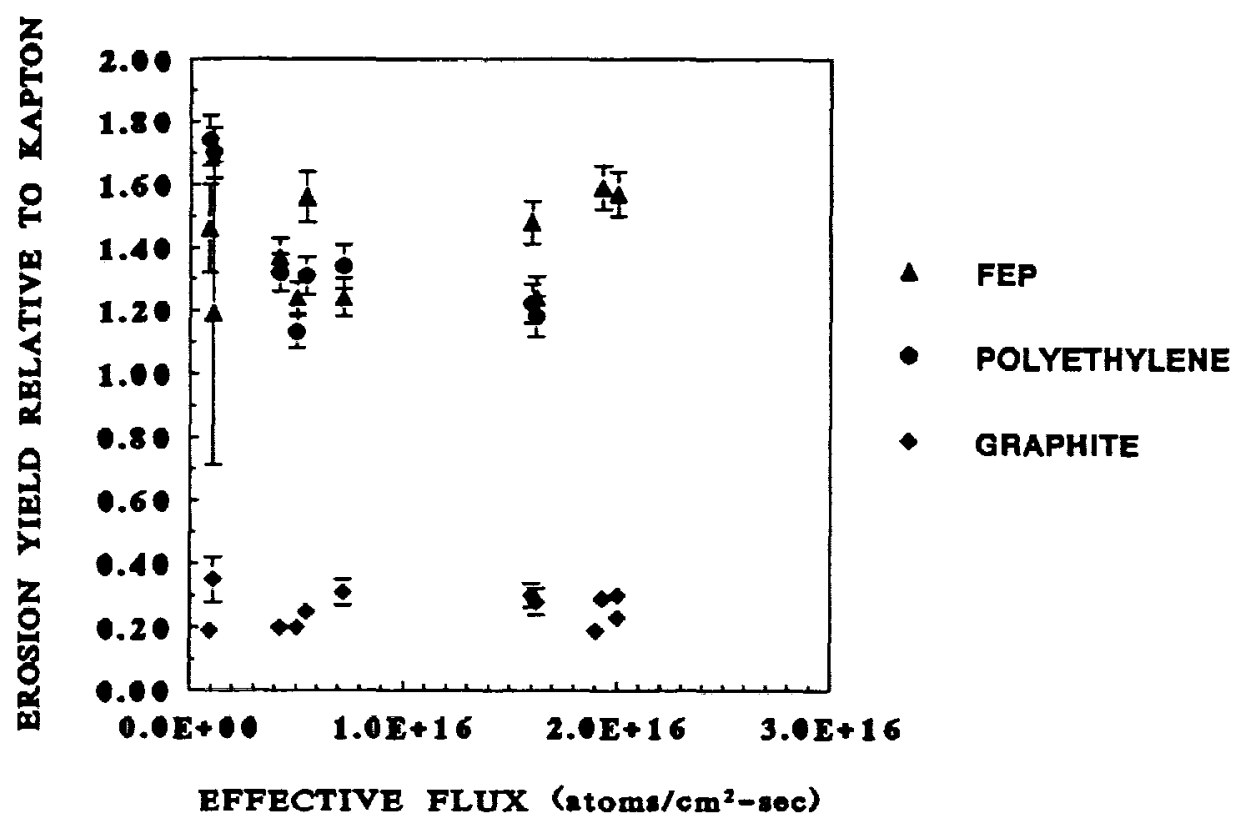

Figure 2.-Relative erosion yield dependence on effective atomic oxygen flux in the directed beam facility. 


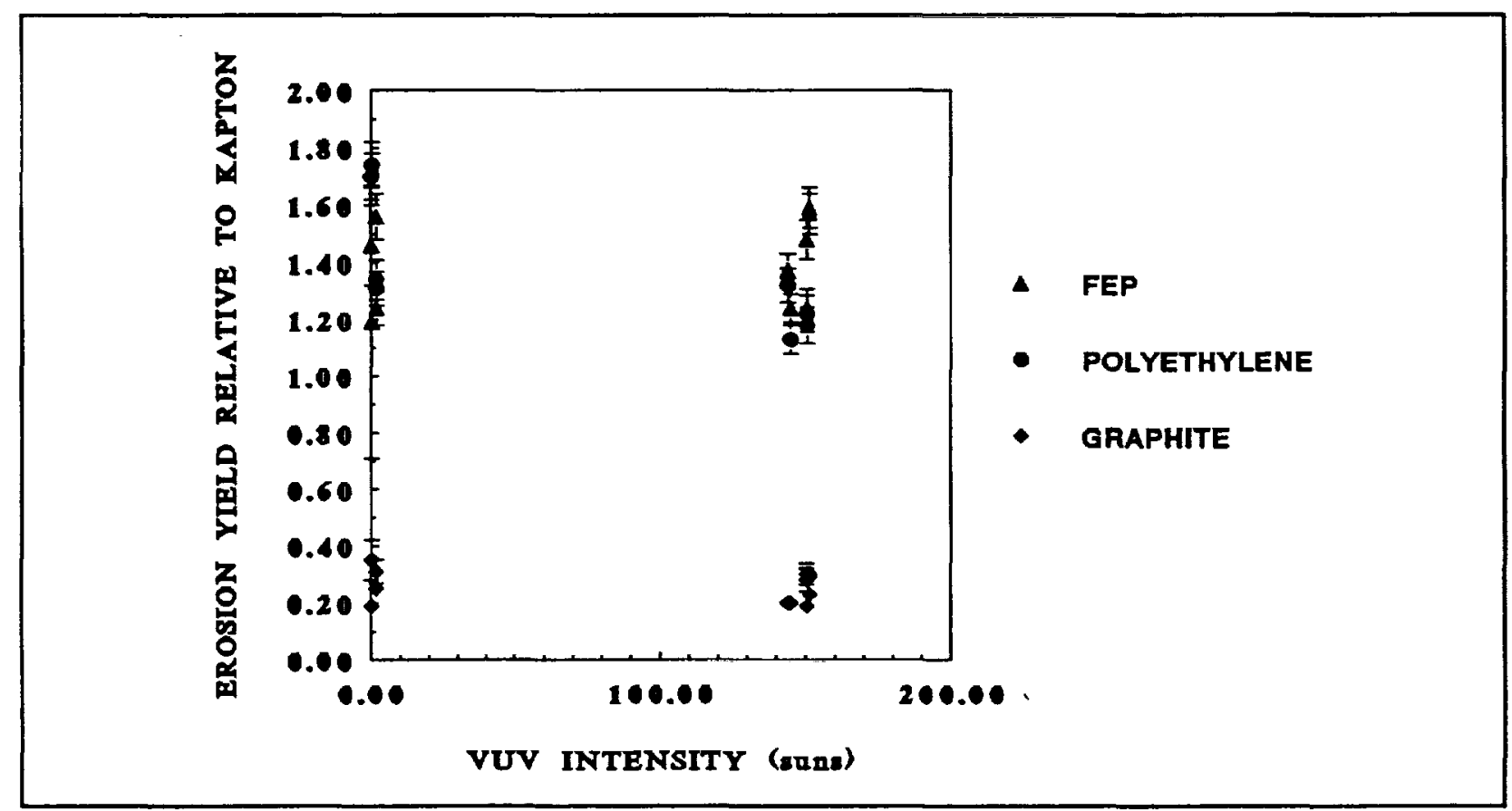

Figure 3.-Relative erosion yield dependence on VUV intensity in the directed beam facility. 
Public reporting burden for this collection of information is estimated to average 1 hour per response, including the time for reviewing instructions, searching existing data sources, gathering and maintaining the data needed, and completing and reviewing the collection of information. Send comments regarding this burden estimate or any other aspect of this
collection of information, including suggestions for reducing this burden, to Washington Headquarters Services, Directorate for Information Operations and Reports, 1215 Jefferson Davis Highway, Sute 1204, Arlington, VA 22202-4302, and to the Office of Management and Budget, Paperwork Reduction Project (0704-0188), Washington, DC 20503.

\begin{tabular}{|l|c|c|}
\hline 1. AGENCY USE ONLY (Leave blank) & $\begin{array}{r}\text { 2. REPOAT DATE } \\
\text { June } 1994\end{array}$ & $\begin{array}{r}\text { 3. REPOAT TYPE AND DATES COVERED } \\
\text { Technical Memorandum }\end{array}$ \\
\hline
\end{tabular}

4. TITLE AND SUBTITLE

A Comparison of Atomic Oxygen Erosion Yields of Carbon and Selected

Polymers Exposed in Ground Based Facilities and in Low Earth Orbit

6. AUTHOR(S)

Sharon K. Rutledge, Bruce A. Banks, and Michael Cales

\section{PERFORMING ORGANIZATION NAME(S) AND ADDRESS(ES)}

National Aeronautics and Space Administration

Lewis Research Center

Cleveland, Ohio 44135-3191

9. SPONSORING/MONITORING AGENCY NAME(S) AND ADDRESS(ES)

National Aeronautics and Space Administration

Washington, D.C. 20546-0001
WU-233-01-0E

8. PERFORMING ORGANIZATION REPORT NUMBEA

E-8910

10. SPONSORINGMONITORING AGENCY REPORT NUMBER

NASA TM-106622

AIAA-94-2628

\section{SUPPLEMENTARY NOTES}

Prepared for the Aerospace Ground Testing Conference sponsored by the American Institute of Aeronautics and Astronautics, Colorado Springs, Colorado, June 20-23, 1994. Sharon K. Rutledge and Bruce A. Banks, NASA Lewis Research Center; and Michael Cales, Cleveland State University, Cleveland, Ohio 44115 (work funded by NASA Cooperative Agreement NCC3-19). Responsible person, Sharon K. Rutledge, organization code 5480, (216) 433-2219.

12a. DISTRIBUTIONAVAILABILITY STATEMENT

12b. DISTRIBUTION CODE

Unclassified - Unlimited

Subject Category 27

13. ABSTRACT (Maximum 200 words)

A comparison of the relative erosion yields (volume of material removed per oxygen atom arriving) for FEP Teflon, polyethylene, and pyrolytic graphite with respect to Kapton $\mathrm{HN}$ was performed in an atomic oxygen directed beam system, in a plasma asher, and in space on the EOIM-III (Evaluation of Oxygen Interaction with Materials-III) flight experiment. This comparison was performed to determine the sensitivity of material reaction to atomic oxygen flux, atomic oxygen fluence, and vacuum ultraviolet radiation for enabling accurate estimates of durability in ground based facilities. The relative erosion yield of pyrolytic graphite was found not to be sensitive to these factors, that for FEP was sensitive slightly to fluence and possibly ions, and that for polyethylene was found to be partially VUV and flux sensitive but more sensitive to an unknown factor. Results indicate that the ability to use these facilities for material relative durability prediction is great as long as the sensitivity of particular materials to conditions such as VUV, and atomic oxygen flux and fluence are taken into account. When testing materials of a particular group such as teflon, it may be best to use a witness sample made of a similar material that has some available space data on it. This would enable one to predict an equivalent exposure in the ground based facility.

14. SUBJECT TERMS

Atomic oxygen; Erosion yields; FEP; Polyethylene; Exposure facilities

15. NUMBER OF PAGES

9

16. PRICE CODE

$\mathrm{A} 02$

\begin{tabular}{|c|c|}
\hline $\begin{array}{c}\text { 17. SECURITY CLASSIFICATION } \\
\text { OF REPORT } \\
\text { Unclassified }\end{array}$ & $\begin{array}{c}\text { 18. SECURITY CLASSIFICATION } \\
\text { OF THIS PAGE } \\
\text { Unclassified }\end{array}$ \\
\hline
\end{tabular}
19. SECURITY CLASSIFICATION OF ABSTRACT Unclassified

